\title{
Short communication: Effects of transition milk and milk replacer supplemented with colostrum replacer on growth and health of dairy calves
}

\author{
B. Van Soest, ${ }^{1}$ F. Cullens, ${ }^{2}$ M. J. VandeHaar, ${ }^{1}$ and M. Weber Nielsen ${ }^{1 *}$ \\ ${ }^{1}$ Department of Animal Science, Michigan State University, East Lansing 48824 \\ ${ }^{2}$ Michigan State Extension, East Lansing 48824
}

\begin{abstract}
Transition milk (TM, defined here as the second through fourth milkings after calving) supplies additional fat, protein, and immunoglobulins to the calf compared with milk replacer at industry-suggested feeding rates $(\sim 14 \%$ solids $)$. Our objective was to determine whether 9 feedings of TM on d 2 through 4 of life increase the growth rate and overall health of calves. Holstein heifer calves on a commercial farm were randomly assigned to 1 of 3 diets $(\mathrm{n}=35 /$ diet $)$ : milk replacer (MR; Purina Warm Front BOV MOS Medicated Milk Replacer, St. Louis, MO), TM, or a 50:50 blend of MR and colostrum replacer (MCR; Alta HiCal Colostrum Powder Replacer, the Saskatoon Colostrum Company Ltd., Saskatoon, SK, Canada). The TM was harvested from Holstein cows on the farm, pooled, and pasteurized at $71.7^{\circ} \mathrm{C}$ for $15 \mathrm{~s}$. Nutrient composition on a dry matter basis of TM was $25.9 \%$ fat, $41.8 \%$ protein, and $14 \%$ solids; MR was $10.3 \%$ fat, $27.8 \%$ protein, and $14 \%$ solids; and MCR was $14.6 \%$ fat, $38.6 \%$ protein, and $15 \%$ solids. All calves received IgG-enriched colostrum replacer for the first 2 feedings after birth. Subsequently, calves were fed $1.9 \mathrm{~L}$ of MR, $\mathrm{TM}$, or MCR 3 times per day for $3 \mathrm{~d}$ (starting on $\mathrm{d}$ $2)$. After initial diets ended, calves were fed and managed similarly. Body weights (d 1, 7, 14, 21, and 56), blood samples (d 1, 7, 14, and 21), and daily health scores (scale of 0 to 3 , with 0 representing normal or healthy and 3 representing severe symptoms or ill) were collected through weaning at $56 \mathrm{~d}$. All except 1 calf achieved successful transfer of passive immunity, with serum IgG values greater than $10.0 \mathrm{mg} / \mathrm{mL}$. From birth through weaning, calves fed TM and MCR gained $3 \mathrm{~kg}$ more total body weight than those fed MR (34.3, 34.3, and $31.3 \mathrm{~kg}$, respectively). Increased metabolizable energy (using NRC 2001 recommendations) in TM accounts for $0.68 \mathrm{~kg}$ of the increased gain compared with MR. Treatment did not alter health scores for ears,
\end{abstract}

Received February 13, 2020.

Accepted July 17, 2020.

*Corresponding author: msw@msu.edu eyes, or feces. Haptoglobin concentrations were lower in TM and MCR than in MR calves $(4.63,3.62$, and $7.54 \mu \mathrm{g} / \mathrm{mL}$, respectively), whereas lipopolysaccharide binding protein concentrations were not different. In conclusion, compared with MR alone, feeding TM or MR with colostrum replacer for $3 \mathrm{~d}$ increased growth rate of calves throughout the preweaning period. Key words: calf, transition milk, milk replacer

\section{Short Communication}

Calves are highly susceptible to disease in the first 4 wk of life (Cho and Yoon, 2014), and $8 \%$ of preweaned heifers die from digestive and respiratory infections (NAHMS, 2011). Enteric diseases are common in wk 1 , and respiratory diseases increase from wk 1 through 4 (Svensson et al., 2003; Hulbert and Moisa, 2016). Diarrhea and bloat affect $25 \%$ of preweaned heifers, and $18 \%$ of calves are treated for these conditions (NAHMS, 2007, 2011). Pneumonia affects $18 \%$ of preweaned heifers, and $16 \%$ receive treatment for pneumonia (NAHMS, 2007, 2011). Supplying calves with adequate nutrition and $\operatorname{IgG}$ are essential management practices for newborn calves to prevent these diseases and promote calf well-being and growth.

The second milking postpartum is considered transition milk (TM; Godden, 2008) and provides 9\% more solids, $65 \%$ more protein, and $52 \%$ more casein and greater amounts of IgG than whole milk at milking 6 . Nutrient concentrations drop gradually until milking 6 , when TM resembles whole milk $(44,13,5,2$, and $2 \mathrm{~g}$ of IgG per liter for milkings 2 through 6; Foley and Otterby, 1978). Additional feedings of colostrum promote maturation of the intestine and increase digestive efficiency (Bühler et al., 1998; Blättler et al., 2001). Also, increasing the number of feedings of colostrum enhances absorptive capacity of the gastrointestinal tract, as measured by increased xylose absorption (Hammon and Blum, 1997). This increase in absorption potentially results from the observed increase in villus height, circumference, and area in the small intestine compared with calves receiving milk replacer. Zhang et al. (2015) reported higher enzyme and immune function-associ- 
ated proteins in colostrum and TM compared with milk at d 9. Feeding TM promotes calf gastrointestinal health and reduces the risk of a poor eye, ear, and nasal scores in calves (Conneely et al., 2014). Although IgG is no longer absorbed into circulation after $24 \mathrm{~h}$ of age (Rayburn et al., 2019), the IgG and other elevated proteins and minerals might produce localized benefits to the digestive tract (Berge et al., 2009). Hammon and Blum (1998) found that calves receiving colostrum showed increased plasma glucose and insulin concentrations, starting at d 2 of life, compared with calves receiving milk replacer. Bovine colostrum has also been shown to be an alternative to antibiotics in human medicine, as it contains antibacterial and antiviral lactoferrins and proinflammatory cytokines (Hagiwara et al., 2000; Furlund et al., 2012) to combat infectious diseases in the gastrointestinal tract (Steele et al., 2013). Feeding supplemental colostrum replacer with milk replacer in the first $14 \mathrm{~d}$ reduced antibiotic use and disease prevalence in preweaned calves (Chamorro et al., 2017).

We hypothesized that supplementing calves from d 2 to 4 of life with TM or a blend of milk replacer and colostrum replacer will improve health scores and growth compared with feeding milk replacer alone. The objective of the present study was to determine the effects of feeding TM or milk replacer supplemented with colostrum replacer on growth and health compared with milk replacer alone.

This study was conducted on a commercial Michigan dairy farm averaging 9 singleborn heifer calves over $25 \mathrm{~kg}$ per week during the months of May through October. The ambient temperature varied from $-4^{\circ} \mathrm{C}$ to $35^{\circ} \mathrm{C}$, with an average temperature of $18.5^{\circ} \mathrm{C}$. All experimental procedures were approved by the Institutional Animal Care and Use Committee of Michigan State University (East Lansing, MI).

Newborn Holstein heifer calves $(\mathrm{n}=105)$ were fed within the first 2 to $6 \mathrm{~h}$ of life $735 \mathrm{~g}$ (DM) of IgGenriched colostrum replacer diluted in $40^{\circ} \mathrm{C}$ water to 2.84 L (Alta Gold Colostrum Powder Replacer, the Saskatoon Colostrum Company Ltd., Saskatoon, SK, Canada; $200 \mathrm{~g}$ of $\mathrm{IgG}$ ). Any refused colostrum replacer was administered via intragastric tube. Calves received an additional $686 \mathrm{~g}$ (DM) of standard colostrum replacer (100 g of IgG; Alta HiCal Colostrum Powder Replacer, the Saskatoon Colostrum Company Ltd.) diluted to $1.89 \mathrm{~L}$ within $12 \mathrm{~h}$ of birth. Once the second feeding was completed, the calves were weighed and transferred from the maternity area to individual hutches bedded with sawdust. The calves were assigned to 1 of 3 treatments by birth order: (1) milk replacer (MR, Purina Warm Front BOV MOS Medicated Milk Replacer, St. Louis, MO), (2) TM, or (3) MR supplemented with colostrum replacer (MCR, Alta HiCal
Colostrum Powder, the Saskatoon Colostrum Company Ltd.), resulting in 35 calves per treatment (Table 1). Treatments were fed for the first 9 feedings on $\mathrm{d} 2$ through 4, following colostrum feedings. All feedings were conducted by farm staff. Milk replacer was fed at $0.8 \mathrm{~kg}(\mathrm{DM}) / \mathrm{d}$ in 3 equal feedings $[140 \mathrm{~g}(\mathrm{DM})$ of powder per liter; $27.8 \% \mathrm{CP}$ and $10.3 \%$ fat on DM basis) and mixed before each feeding according to the manufacturer's recommendations, supplying 1.17 Mcal per feeding of $1.89 \mathrm{~L}$. The TM for this study was collected starting 4 mo before the start of the trial from the same commercial dairy herd in which the study was held. The TM was harvested at milkings 2 through 4 after calving and stored at $-20^{\circ} \mathrm{C}$. Then the TM was thawed at room temperature, pooled, and pasteurized at $71.7^{\circ} \mathrm{C}$ for 15 s. Samples were collected before and after pasteurization for nutrient and IgG analysis. The TM was then measured into 1.89-L quantities, sealed in colostrum bags (Colo Quick, Golden Calf Co., Bloomer, WI), and frozen at $-20^{\circ} \mathrm{C}$ until feeding. Prior to feeding, the bags were placed into a thaw unit (Calf Hero, Golden Calf Co.) to heat to $41^{\circ} \mathrm{C}$. Before pasteurization, the TM contained $4.39 \%$ fat, $7.08 \%$ protein, $4.38 \%$ lactose, and $29.5 \mathrm{~g}$ of $\operatorname{IgG}$ per liter as fed. After pasteurization, the TM contained $3.79 \%$ fat, $6.10 \%$ protein, $3.81 \%$ lactose, and $1.5 \mathrm{~g}$ of $\mathrm{IgG}$ per liter as fed, and was calculated to contain 1.44 Mcal ME per 1.89 L. The calves received $0.9 \mathrm{~kg}(\mathrm{DM})$ per day of TM, divided into 3 equal feedings. The MCR diet consisted of $147 \mathrm{~g}$ (DM) of milk replacer and $143 \mathrm{~g}(\mathrm{DM})$ of the standard colostrum replacer powder per feeding. This formula was designed to mimic a transition milk-like diet, supplying the calves with $15 \mathrm{~g} / \mathrm{L}$ of IgG. The caloric intake of MCR was 1.28 Mcal of ME per 1.89 L (NRC, 2001). Diets were fed at a constant volume $(1.9 \mathrm{~L} /$ feeding $)$ without adjusting for individual calves' birth weight. Calves were fed 3 times a day at 0400, 1200, and 1800 h. Birth date, weight, and time; colostrum volume and time fed; and treatment were recorded. On d 5 , after calves received their final feeding of treatment diets, all calves were managed and fed similarly, receiving MR until weaning at $\mathrm{d} 56$. Refusals were recorded by calf feeders to the nearest $0.473 \mathrm{~L}$ (1 pint) for all liquid feed until weaning. Calves were fed the same milk replacer fed to the MR group, as follows: end of treatment to $14 \mathrm{~d}$ of age, $0.8 \mathrm{~kg}(\mathrm{DM})$ per day in 3 daily feedings; 15 to $41 \mathrm{~d}$ of age, $1.2 \mathrm{~kg}(\mathrm{DM})$ per day in 3 daily feedings; 42 to $48 \mathrm{~d}$ of age, $0.8 \mathrm{~kg}(\mathrm{DM})$ per day in 2 daily feedings; and 49 to $56 \mathrm{~d}$ of age, $0.4 \mathrm{~kg}(\mathrm{DM})$ per day in 1 feeding. Calf starter grain mix (Ampli-Calf, Purina: 20\% CP, 2.5\% crude fat, $7.5 \%$ crude fiber, and $9 \% \mathrm{ADF}$ as fed) and water were available ad libitum in the pen starting on d 2. Calves were disbudded by cautery between 5 and $12 \mathrm{~d}$ of age by farm staff. The calves were checked daily 
Table 1. Chemical composition of milk replacer, transition milk, and a 1:1 mix of milk replacer and colostrum replacer fed to calves from 2 to $4 \mathrm{~d}$ of age, nutrient intake, and predicted ADG

\begin{tabular}{lccc}
\hline & \multicolumn{3}{c}{ Diet $^{1}$} \\
\cline { 2 - 4 } Variable & MR & TM & MCR \\
\hline Fat (\% on DM basis) & 10.3 & 25.9 & 14.6 \\
Protein (\% on DM basis) & 27.8 & 41.8 & 38.6 \\
IgG (g/kg of DM) & 0 & 10 & 98 \\
ME (Mcal/kg of DM) & 4.03 & 5.40 & 4.47 \\
DMI $(\mathrm{g} / \mathrm{d})$ & 770 & 862 & 864 \\
$\mathrm{CP} \mathrm{intake}^{2}(\mathrm{~g} / \mathrm{d})$ & 214 & 360 & 332 \\
ME intake $^{2}\left(\mathrm{Mcal}^{2} \mathrm{~d}\right)$ & 3.10 & 4.65 & 3.86 \\
Expected $^{\mathrm{ADG}}{ }^{2}(\mathrm{~kg} / \mathrm{d})$ & 0.59 & 1.02 & 0.78 \\
\hline
\end{tabular}

${ }^{1}$ Diets contained milk replacer (MR), pooled and pasteurized transition milk (TM), or MR supplemented at a ratio of 1:1 with colostrum replacement powder (MCR). Composition of nutrients in MR and MCR were provided by manufacturers (MR: Purina Warm Front BOV MOS Medicated Milk Replacer, St. Louis, MO; MCR: Alta HiCal Colostrum Powder Replacer, the Saskatoon Colostrum Company Ltd., Saskatoon, SK, Canada), and TM composition was determined by CentralStar Laboratory (Grand Ledge, MI), using near-infrared spectroscopy to measure fat and total protein contents of unhomogenized milk. Concentrations of IgG were determined by Saskatoon Colostrum Co., using a radial immunodiffusion assay.

${ }^{2}$ Average daily intake of DM, CP, ME, or expected ADG (NRC, 2001) during the treatment period (d 2-4).

and treated for health issues by farm staff, following established protocols, and checked once a week by the farm veterinarian.

Blood was collected via jugular venipuncture using evacuated tubes (BD Vacutainer Venous Blood Collection Tubes: Vacutainer Plus Glass Serum Tube; Becton, Dickinson and Company, Franklin Lakes, NJ) and 21-gauge blood collection needles (Monoject, Kendall Tyco Healthcare, Mansfield, MA) at 24 to $48 \mathrm{~h}$ of age and at $7 \pm 1,14 \pm 1$, and $21 \pm 1 \mathrm{~d}$ of age. Once blood samples clotted at room temperature, samples were centrifuged at $1,700 \times g$ for $15 \mathrm{~min}$ at $4^{\circ} \mathrm{C}$. Serum was harvested and stored at $-20^{\circ} \mathrm{C}$. Haptoglobin and LPS binding protein (LBP) were analyzed in blood samples from d 14 and d 21 (Bovine Haptoglobin ELISA Kit, Immunology Consultants Laboratory Inc., Portland, OR; and LBP Various Species Kit, Hycult Biotech HK503 Edition, Uden, the Netherlands, respectively). Observational health scores were recorded daily from birth through the first 3 wk $(21 \mathrm{~d})$ of age. Scores were recorded for fecal consistency, ear disposition, and eye discharge using the Calf Health Scoring Chart (University of Madison-Wisconsin School of Veterinary Medicine; https://www.vetmed.wisc.edu/fapm/svm-dairy -apps/calf-health-scorer-chs/). Health events were scored on a scale of 0 through 3 , with 0 representing normal or healthy and 3 representing severe symptoms or ill. Health scores for each animal were summed for feces, ear, and eye separately for the first $21 \mathrm{~d}$ of life.
Once summed, scores were then averaged by treatment to yield final scores to compare treatments.

Data were analyzed for statistical differences using the Mixed procedure in SAS 9.4 (SAS Institute Inc., Cary, NC). Our model included the fixed effect of treatment and random effect of block, with preplanned contrasts for (1) MR versus TM and MCR and (2) TM versus MCR. Data are shown using a preplanned contrast. Birth weight was used as a covariate in the calculations of BW gain. Significance was denoted at $P$ $\leq 0.05$, and tendencies were denoted at $P$-values $\leq 0.1$ and $>0.05$ for all main effects.

Treatment did not alter fecal, ear, or eye scores (Table 2). During the study, only $17 \%$ of calves were treated, and $<1 \%$ died, making it difficult to detect any health differences observationally. When summing the scores, the maximum possible score a calf could receive was 63 . Average health scores were all $<8$, and mortality was $<1 \%$, indicating that all treated animals had excellent health. We speculate that if the farm had experienced more health problems, perhaps differences among treatments would have been apparent. Both TM and MCR reduced haptoglobin concentrations to $4.63 \mu \mathrm{g} / \mathrm{mL}$ and $3.62 \mu \mathrm{g} / \mathrm{mL}$, respectively, whereas $\mathrm{MR}$ was at $7.54 \mu \mathrm{g} / \mathrm{mL}(P=0.05)$; and $\mathrm{TM}$ and MCR were not different $(P=0.59)$. Haptoglobin increases in response to inflammatory stimuli (Morimatsu et al., 1992; Nakajima et al., 1993); therefore, our results indicate that TM and MCR reduced overall inflammation from d 7 through 21 of life. Haptoglobin concentrations in healthy calves have been defined as $<350 \mu \mathrm{g} / \mathrm{mL}$ (Horadagoda et al., 1994) or $<50 \mu \mathrm{g} / \mathrm{mL}$ (Gelsinger et al., 2016), indicating that the calves were healthy, with the average haptoglobin concentration well below both thresholds. Treatment did not affect serum concentration of LBP when comparing MR to TM and MCR or between TM and MCR $(P=0.42$ and 0.68 , respectively). Concentrations of LBP were 5.76, 5.27, and $5.49 \mu \mathrm{g} / \mathrm{mL}$ for MR, MCR, and TM, respectively. Overall, treatment did not affect health measures, possibly due to good farm hygiene or because the levels of bioactive components and additional IgG within the diets were not adequate to elicit a benefit.

Both TM and MCR increased BW gain through weaning by $3.0 \mathrm{~kg}(P=0.02$; Table 3$)$, with gains of $34.2 \mathrm{~kg}$ and $34.3 \mathrm{~kg}$, compared with MR $31.3 \mathrm{~kg}$. We detected no difference when comparing TM with MCR $(P=0.9)$. When considering ADG, the MR calves gained $0.56 \mathrm{~kg} / \mathrm{d}$, whereas TM and MCR both gained $0.62 \mathrm{~kg} / \mathrm{d}$ through the preweaning period $(P=0.01$; Table 3). Based on NRC 2001 equations, the additional energy consumed by TM and MCR compared with MR calves in the first week of life would account for $1.29 \mathrm{~kg}$ of gain in TM calves and $0.57 \mathrm{~kg}$ in MCR, of the $3.0-\mathrm{kg}$ 
Table 2. Biomarkers of inflammation and health scores (scores averaged by calf for the first $21 \mathrm{~d}$ of age)

\begin{tabular}{|c|c|c|c|c|c|c|}
\hline \multirow[b]{2}{*}{ Variable } & \multicolumn{3}{|c|}{ Diet $^{1}$} & \multirow[b]{2}{*}{ SEM } & \multicolumn{2}{|c|}{$P$-value } \\
\hline & MR & TM & MCR & & $\begin{array}{l}\text { MR vs. TM } \\
\text { and } \mathrm{MCR}^{2}\end{array}$ & $\begin{array}{l}\text { TM vs. } \\
\text { MCR }^{3}\end{array}$ \\
\hline Eye $^{4}$ & 0.60 & 0.31 & 0.30 & 0.16 & 0.13 & 0.9 \\
\hline Feces $^{4}$ & 6.8 & 7.8 & 7.2 & 0.83 & 0.4 & 0.6 \\
\hline $\operatorname{Ear}^{4}$ & 2.4 & 2.3 & 2.6 & 0.42 & 0.9 & 0.6 \\
\hline Haptoglobin $^{5}(\mu \mathrm{g} / \mathrm{mL})$ & 7.5 & 4.6 & 3.6 & 1.40 & 0.05 & 0.6 \\
\hline $\mathrm{LBP}^{6}(\mu \mathrm{g} / \mathrm{mL})$ & 5.8 & 5.5 & 5.3 & 0.45 & 0.4 & 0.7 \\
\hline \multicolumn{7}{|c|}{$\begin{array}{l}{ }^{1} \text { Diets contained milk replacer (MR), pooled and pasteurized transition milk (TM), or milk replacer suppl } \\
\text { mented at a ratio of 1:1 with colostrum replacement powder (MCR). }\end{array}$} \\
\hline \multicolumn{7}{|c|}{${ }^{2}$ Contrast of MR and treatments TM and MCR. } \\
\hline \multicolumn{7}{|c|}{${ }^{3}$ Contrast of TM and MCR. } \\
\hline \multicolumn{7}{|c|}{${ }^{4}$ Daily health scores averaged by calf for the first $21 \mathrm{~d}$. } \\
\hline \multicolumn{7}{|c|}{${ }^{5}$ Haptoglobin samples from d 14 and 21.} \\
\hline
\end{tabular}

difference at weaning. Once the gain was adjusted to incorporate the difference in ME, TM and MCR numerically increased BW gain by $2.0 \mathrm{~kg}$ compared with MR calves, but the effect was no longer significant $(P=$ $0.13)$. No treatment effect was observed on refusals in the 9 feedings of the respective treatments (9\% refusals for all diets). After d 4 until weaning (d 56), all treatment groups averaged $0.40 \%$ refusals of milk replacer. We did not measure starter or water intake during the study to assess their potential contribution to BW gain. However, any differences in water, starter, or milk intake following d 4 would be treatment responses, not part of the treatments. Additional feedings of colostrum or TM supply not only additional nutrients but also other beneficial bioactive components, such as IgG, insulin, vitamins $\mathrm{A}, \mathrm{E}$, and $\mathrm{B} 12$, manganese, iron, cobalt, zinc, riboflavin, and choline (Foley and Otterby, 1978). Also, TM is known to contain microRNAs and bioactive proteins (Fahey et al., 2020; Van Hese et al., 2020). Colostrum and TM promote earlier development of the intestinal tract (Hammon and Blum 1997; Rauprich et al., 2000; Blättler et al., 2001) and elicit localized im- munity within the gut (Berge et al., 2009; Chamorro et al., 2017). We speculate that these components in TM or MCR also promoted earlier intestinal development and localized immunity in our TM calves, resulting in increased weight gain. We also speculate that this might have longer-term benefits, because increased nutrient intake, accompanied by elevated growth rates, can hasten conception and increase milk production in the first lactation (Davis Rincker et al., 2011).

The present study demonstrated that feeding additional nutrients and bioactive compounds in the form of TM or colostrum replacer for the first $4 \mathrm{~d}$ of life increases growth up to the time of weaning, along with decreasing serum haptoglobin concentrations. We conclude that feeding TM or MCR for the first $4 \mathrm{~d}$ of life can improve health and increase the rate of $\mathrm{BW}$ gain of calves. Whether this increase would translate into improved performance later in life is not clear. Exploiting nutritional strategies to enhance calf growth in the first few days of life offers potential to improve weight gain and health throughout the preweaning period and after.

Table 3. Initial BW, weaning weight, and gain for calves fed experimental diets

\begin{tabular}{|c|c|c|c|c|c|c|}
\hline \multirow[b]{2}{*}{ Variable } & \multicolumn{3}{|c|}{$\operatorname{Diet}^{1}$} & \multirow[b]{2}{*}{ SEM } & \multicolumn{2}{|c|}{$P$-value } \\
\hline & MR & $\mathrm{TM}$ & MCR & & $\begin{array}{c}\text { MR vs. TM } \\
\text { and } \mathrm{MCR}^{2}\end{array}$ & $\begin{array}{l}\text { TM vs. } \\
\text { MCR }^{3}\end{array}$ \\
\hline Weaning weight $(\mathrm{kg})$ & $68.1 \pm 6.8$ & $71.8 \pm 5.3$ & $73.0 \pm 6.6$ & 1.01 & $<0.01$ & 0.7 \\
\hline Weight gain $(\mathrm{kg})$ & $31.3 \pm 5.8$ & $34.2 \pm 6.0$ & $34.3 \pm 6.2$ & 0.98 & 0.02 & 0.9 \\
\hline Preweaning ADG $(\mathrm{kg} / \mathrm{d})$ & $0.562 \pm 0.10$ & $0.616 \pm 0.14$ & $0.620 \pm 0.11$ & 0.017 & 0.01 & 0.9 \\
\hline
\end{tabular}

${ }^{1}$ Diets contained milk replacer (MR), pooled and pasteurized transition milk (TM), or milk replacer supplemented at a ratio of $1: 1$ with colostrum replacement powder (MCR). Means reported $\pm \mathrm{SD}$.

${ }^{2}$ Contrast of MR and treatments TM and MCR.

${ }^{3}$ Contrast of TM and MCR. 


\section{ACKNOWLEDGMENTS}

The authors acknowledge J. S. Liesman (Michigan State, East Lansing, MI) and the staff at Nobis Dairy Farm (St. Johns, MI) for their assistance in this experiment. This project was supported by the Michigan Alliance for Animal Agriculture (East Lansing, MI) and the Saskatoon Colostrum Company (Saskatoon, SK, Canada). The authors have not stated any conflicts of interest.

\section{REFERENCES}

Berge, A. C. B., T. E. Besser, D. A. Moore, and W. M. Sischo. 2009. Evaluation of the effects of oral colostrum supplementation during the first fourteen days on the health and performance of preweaned calves. J. Dairy Sci. 92:286-295. https://doi.org/10.3168/ jds.2008-1433.

Blättler, U., H. M. Hammon, C. Morel, C. Philipona, A. Rauprich, V. Rome, I. Le Huerou-Luron, P. Guilloteau, and J. W. Blum. 2001. Feeding colostrum, its composition and feeding duration variably modify proliferation and morphology of the intestine and digestive enzyme activities of neonatal calves. J. Nutr. 131:1256-1263. https://doi.org/10.1093/jn/131.4.1256.

Bühler, C., H. M. Hammon, G. L. Rossi, and J. W. Blum. 1998. Small intestinal morphology in eight-day-old calves fed colostrum for different durations or only milk replacer and treated with long-R3insulin-like growth factor I and growth hormone. J. Anim. Sci. 76:758-765. https://doi.org/10.2527/1998.763758x.

Chamorro, M. F., N. Cernicchiaro, and D. M. Haines. 2017. Evaluation of the effects of colostrum replacer supplementation of the milk replacer ration on the occurrence of disease, antibiotic therapy, and performance of pre-weaned dairy calves. J. Dairy Sci. 100:1378-1387. https://doi.org/10.3168/jds.2016-11652.

Cho, Y. I., and K. J. Yoon. 2014. An overview of calf diarrhea-Infectious etiology, diagnosis and intervention. J. Vet. Sci. 15:1-17. https://doi.org/10.4142/jvs.2014.15.1.1.

Conneely, M., D. P. Berry, J. P. Murphy, I. Lorenz, M. L. Doherty, and E. Kennedy. 2014. Effect of feeding colostrum at different volumes and subsequent number of transition milk feeds on the serum immunoglobulin G concentration and health status of dairy calves. J. Dairy Sci. 97:6991-7000. https://doi.org/10.3168/jds.2013-7494.

Davis Rincker, L. E., M. J. VandeHaar, C. A. Wolf, J. S. Liesman, L. T. Chapin, and M. S. Weber Nielsen. 2011. Effect of intensified feeding of heifer calves on growth, pubertal age, calving age, milk yield, and economics. J. Dairy Sci. 94:3554-3567. https://doi.org/ 10.3168/jds.2010-3923.

Fahey, M. J., A. J. Fischer, M. A. Steele, and S. L. Greenwood. 2020. Characterization of the colostrum and transition milk proteomes from primiparous and multiparous Holstein dairy cows. J. Dairy Sci. 103:1993-2005. https://doi.org/10.3168/jds.2019-17094.

Foley, J. A., and D. E. Otterby. 1978. Availability, storage, treatment, composition, and feeding value of surplus colostrum: A review. J. Dairy Sci. 61:1033-1060. https://doi.org/10.3168/jds.S0022 -0302(78)83686-8.

Furlund, C.B., A.B. Kirstoffersen, T.G. Devold, G.E. Vergarud, and C.M. Jnassen. 2012. Bovine lactoferrin digested with human gastrointestinal enzymes inhibits replication of human echovirus in cell culture. Nutr. Res. 32:503-513. https://doi.org/10.1016/j .nutres.2012.06.006.

Gelsinger, S. L., F. Pino, C. M. Jones, A. M. Gehman, and A. J. Heinrichs. 2016. Effects of a dietary organic mineral program including mannan oligosaccharides for pregnant cattle and their calves on calf health and performance. Prof. Anim. Sci. 32:205-213. https:/ /doi.org/10.15232/pas.2015-01475.

Godden, S. 2008. Colostrum management for dairy calves. Vet. Clin. North Am. Food Anim. Pract. 24:19-39. https://doi.org/10.1016/ j.cvfa.2007.10.005.
Hagiwara, K., S. Kataoka, H. Yamanaka, R. Kirisawa, and H. Iwai. 2000. Detection of cytokines in bovine colostrum. Vet. Immunol. Immunopathol. 76:183-190. https://doi.org/10.1016/S0165 -2427(00)00213-0.

Hammon, H., and J. W. Blum. 1997. Prolonged colostrum feeding enhances xylose absorption in neonatal calves. J. Anim. Sci. 75:29152919. https://doi.org/10.2527/1997.75112915x.

Hammon, H., and J. W. Blum. 1998. Metabolic and endocrine traits of neonatal calves are influenced by feeding colostrum for different durations or only milk replacer. J. Nutr. 128:624-632. https://doi .org/10.1093/jn/128.3.624.

Horadagoda, A., P. D. Eckersall, J. C. Hodgson, H. A. Gibbs, and G. M. Moon. 1994. Immediate responses in serum TNFo and acute phase protein concentrations to infection with Pasteurella haemolytica A1 in calves. Res. Vet. Sci. 57:129-132. https://doi.org/10 .1016/0034-5288(94)90094-9.

Hulbert, L. E., and S. J. Moisa. 2016. Stress, immunity, and the management of calves. J. Dairy Sci. 99:3199-3216. https://doi.org/10 $.3168 /$ jds.2015-10198.

Morimatsu, M., M. Sarikaputi, B. Syuto, M. Saito, S. Yamamoto, and M. Naiki. 1992. Bovine haptoglobin: Single radial immunodiffusion assay of its polymeric forms and dramatic rise in acute-phase sera. Vet. Immunol. Immunopathol. 33:365-372. https://doi.org/ 10.1016/0165-2427(92)90007-D.

NAHMS (National Animal Health Monitoring System). 2007. Dairy 2007. Part I: Reference of Dairy Health and Management in the United States, 2007. United States Dept. Agric., Anim. Plant Health Inspec. Serv., Vet. Serv., Fort Collins, CO. Accessed Jul. 22, 2019. http://www.aphis.usda.gov/animal_health/nahms/ dairy/index.shtml.

NAHMS (National Animal Health Monitoring System). 2011. Dairy 2011. Dairy Heifer Raiser, 2011. United States Dept. Agric., Anim. Plant Health Inspection. Serv., Vet. Serv., Fort Collins, CO. Accessed Dec. 20, 2019. http://www.aphis.usda.gov/animal_health/ nahms/dairy/index.shtml.

Nakajima, Y., E. Momotani, T. Murakami, Y. Ishikawa, M. Morimatsu, M. Saito, H. Suzuki, and K. Yasukawa. 1993. Induction of acute phase protein by recombinant human interleukin-6 (IL-6) in calves. Vet. Immunol. Immunopathol. 35:385-391. https://doi .org/10.1016/0165-2427(93)90047-8.

NRC (National Research Council). 2001. Nutrient Requirements of Dairy Cattle. National Academies Press, Washington, DC.

Rauprich, A. B. E., H. M. Hammon, and J. W. Blum. 2000. Influence of feeding different amounts of first colostrum on metabolic, endocrine, and health status and on growth performance in neonatal calves. J. Anim. Sci. 78:896-908. https://doi.org/10.2527/ 2000.784896x.

Rayburn, M. C., M. Chigerwe, J. Barry, and E. Kennedy. 2019. Short communication: Use of a digital refractometer in assessing immunoglobulin $\mathrm{G}$ concentrations in colostrum and the first 5 transition milkings in an Irish dairy herd. J. Dairy Sci. 102:7459-7463. https: //doi.org/10.3168/jds.2019-16467.

Steele, J., J. Sponseller, D. Schmidt, O. Cohen, and S. Tzipori. 2013. Hyperimmune bovine colostrum for treatment of GI infections: A review and update on Clostridium difficile. Hum. Vaccin. Immunother. 9:1565-1568. https://doi.org/10.4161/hv.24078.

Svensson, C., K. Lundborg, U. Emanuelson, and S. O. Olsson. 2003. Morbidity in Swedish dairy calves from birth to 90 days of age and individual calf-level risk factors for infectious diseases. Prev. Vet. Med. 58:179-197. https://doi.org/10.1016/S0167-5877(03)00046 -1 .

Van Hese, I., K. Goossens, L. Vandaele, and G. Opsomer. 2020. Invited review: MicroRNAs in bovine colostrum- Focus on their origin and potential health benefits for the calf. J. Dairy Sci. 103:1-15. https: //doi.org/10.3168/jds.2019-16959.

Zhang, L., S. Boeren, J.A. Hageman, T. van Hooijdonk, J. Vervoort, and K. Hettinga. 2015. Bovine milk proteome in the first 9 days: Protein interactions in maturation of the immune and digestive system of the newborn. PLoS One 10:e0116710. https://doi.org/10 .1371/journal.pone.0116710. 